\title{
You have an academic job offer...Now what? Negotiating advice from two perspectives
}

\author{
William O'Brochtal and Lori Poloni-Staudinger ${ }^{2}$
}

Congratulations on receiving a job offer! Any job offer is a time to celebrate and then to consider your next steps. Successful job negotiations establish a collegial relationship between the job candidate and the negotiating institution while at the same time providing an opportunity for the job candidate to ask for additional resources that help to ensure success at that institution. Negotiating a job offer is a new experience for many graduate students, and the excitement of receiving the offer may provoke an urge to accept the offer immediately. Most job offers are extended on the phone, so we recommend conveying your enthusiasm about the position, asking to receive the details of the offer via email, and asking for some time to consider the offer. Negotiating institutions should be more than understanding of these requests- perhaps even offering to communicate the offer in writing and to give you time to consider the offer without you needing to ask. Negotiation is an expected part of the job search process and one that is critically important, particularly given known inequities in negotiation outcomes (e.g., Claypool et al. 2017). Salary, research funding, teaching load, sabbatical opportunities, and moving expenses are just a few of an almost endless list of potential negotiation items. The exact list of items over which you negotiate depends on both your needs and the resources available at the negotiating institution.

This chapter discusses strategies for navigating the time between receiving an offer phone call and signing a job contract, drawing first on the experiences of a dean who frequently engages in negotiations and then from a faculty member who recently went through the negotiation process. We begin by discussing common pitfalls to avoid during the negotiation process, following this with strategies for making negotiation easier and more successful. We conclude by describing the process of accepting a job offer and signing a job contract.

\section{A Dean's Four Negotiation Pitfalls}

As an administrator with experience negotiating with new faculty across several disciplines and in several different types of administrative positions- department chair, associate dean, and dean - I have seen common patterns emerge related to the "dos and don'ts" of negotiation. I will cover four key pitfalls candidates often make here.

\footnotetext{
${ }^{1}$ Assistant Professor of Political Science, School of History and Social Science, Louisiana Tech University, 1308 West Railroad Avenue, Ruston, Louisiana 71272. obrochta@latech.edu.

${ }^{2}$ Interim Dean, College of Social and Behavioral Sciences and Professor, Department of Politics and International Affairs, Northern Arizona University, P.O. Box 15700, Flagstaff, Arizona 86011. lori.poloni-staudinger@nau.edu.
} 
First, be confident, but not condescending. You worked hard; you got a Ph.D.; you should be proud. You should also remember that the person sitting across the proverbial negotiating table from you also has worked hard. They are likely in a senior position and most definitely in an administrative position. They most likely do not rest on the laurels of their advisor or their doctoral program; they have achieved success in their own right. Why is this important? Most students come out of graduate programs of a higher rank than that where they are seeking employment. The person you are negotiating with has been in the profession for much longer than you. You should be confident in your skills, but you should not be condescending to the person with whom you are negotiating. Don't name drop. Be aware of your implicit biases and make sure these are not showing through in your negotiations. Implicit bias is when we have a preference for (or aversion to) a person or group of people (Perception Institute 2021). It is implicit because it is an unconscious attitude (see implicit.harvard.edu for more on implicit biases or to test your own). This is a sure way to start off on a bad foot with a person you will need later for everything from finishing up your negotiation to asking for indexing fees for your first book. You want the administrator to leave the negotiation feeling like you are bright and confident, but not like you tried to "one up" them. At the same time, be aware that deans also come with their own implicit biases. For example, there is some research out of the corporate world that indicates that women can be "punished" for negotiating (Shonk 2021). When you are aware of these biases, you can use the negotiation as an opportunity to educate, to inform and to turn the negotiation in your favor.

Second, if you don't ask, you're not going to get it. But don't go too far. I tell candidates, "give me your holiday wish list, but don't ask for a unicorn." In other words, be reasonable. Usually a chair or dean will tell you if they can't budge on something like salary, but they are able to do more in start-up or summer funding. Often moving expenses are capped in public institutions based on state mandates. If you are coming up with nothing but no, ask where there might be room for negotiation. The institution has decided they want you, but in most cases, they aren't going to be willing to get you at all costs. The academic labor market is a market like any other market with supply and demand. Keep this in mind. Make a list of things you would like to negotiate on and be prepared to walk away from some of them. At the same time, be prepared to ask. Some people, particularly women, have anxiety with negotiating (Barron 2003). Practice with a friend or with yourself in the mirror so that you can ask with confidence (see point 1 above). While advisors can be helpful with what to ask for, they likely were placed at an institution with a higher rank and more resources (your doctoral institution) than where you got your offer, and in most cases, they were negotiating under different market conditions. Reach out to peers from similar types of institutions to where you got an offer and seek their advice on areas where you can negotiate.

Third, keep perspective on your place in the institution and the larger institutional community. It is important that you research and understand the larger institutional context. Is the institution mainly a teaching institution? If so, you may not be able to negotiate a reduced teaching load, but you may be able to ask for summer pay and an undergraduate research assistant. Does the unit have a graduate program? Could you ask for a graduate assistant for a period of time to help on a research project while also securing funding for a student? Understanding the institution also means understanding how your new department is situated in the larger institution. If you are going into a unit that is expected to generate general studies seats for the institution, you may 
find better luck asking for software or grading help than a pre-tenure sabbatical. If instead you are entering a unit where grant writing is common and expected, negotiating that term off may be an easier sell. It is also important that you understand the financial situation of the institution. Has it suffered from years of budget cuts? If so, negotiating on salary may be difficult as it will likely cause salary compression with colleagues who haven't had raises in several years. In short, know your audience and ask for things that make sense in the context in which you will be embedded.

Finally, have perspective on the unit. You should do your homework and see what other faculty's workloads and salaries look like. If you are negotiating with a public institution, this information is often available. Make sure that you are aligning your requests to be in line with what is common in your new department. Some administrators are very concerned with compression. This means there may be a top salary bar above which they absolutely won't go over because to do so would bring you in at a higher rate than colleagues with more experience. In these instances, seek alternative areas of negotiation. The same advice goes for negotiating on teaching load. Be sure to understand what the norm is among your new colleagues. If all faculty are on a 3-3 load (or a 3-3-3 for an institution on a quarter system), asking for a 0-1 is probably not realistic. You would stand a better chance of getting a yes by asking for a 2-2 for the first year, 3-2 the second year and 3-3 thereafter. Remember, these will be your future colleagues. You do not want to start off making an impression that you expected to be treated better or differently than others in the unit. You want to build a spirit of collegiality from the first moments of negotiation until you step on to campus.

\section{A Faculty Member's Strategies for Successful Negotiations}

Given these potential pitfalls, what are ways for you as a job candidate to increase your chances of conducting a successful negotiation? My main suggestion is to plan for the negotiation carefully and strategically. This may seem like obvious advice, but each negotiation has its own set of circumstances, opportunities, and challenges.

First, approach the negotiation from the perspective of a new faculty member and colleague. You may end up accepting the job offer, so a confrontational negotiation process could create a negative first impression. You can avoid confrontation by clearly understanding who you are negotiating with and what their timeline is. You may negotiate with a department chair or a dean who then must take your list of negotiation items to someone else in the institution for approval instead of speaking with that person directly. In these cases, the person you are negotiating with is your messenger for the negotiation, so clearly explaining how each of your requests will benefit both you and the institution will help them to make your case to the approving authority. Confronting the messenger only serves to hurt your case. Similarly, some institutions must end negotiations quickly for a wide variety of reasons. Aim for only one round of negotiations, so as not to drag the process along, especially when doing so presents challenges for the institution. Negotiating is rarely anyone's favorite part of the job search process, so keeping the negotiation friendly will improve your likelihood of success and reduce everyone's anxiety.

Negotiations often become confrontational when job candidates focus on negotiation items that institutions simply do not have the resources or ability to provide. As you view negotiating from 
the perspective of a new colleague at the institution, prepare yourself. Written offers often contain limited information. Some items that you may be interested in discussing during a negotiation- like parental leave or sabbaticals- may be listed in formal institutional policies or on the websites of various institutional departments. Salaries are often public information at many state institutions, and you may find that there is a state-mandated salary range. Checking for this information on your own before asking helps to show that you are taking the negotiation seriously and allows you to focus your requests on key items that the institution does not already provide to all employees.

One excellent way to find out about the norms surrounding negotiating at a particular institution is to informally ask faculty you met during your interview. Once they have decided to extend you a job offer, faculty members want you to come to their institution. Many times, they will reach out to you offering to talk or to answer questions about the position. Otherwise, reach out and ask to talk informally to faculty. This is a perfect time to get to know your new colleagues a bit better and to ask informally about negotiation items. Asking non-specific questions like "can you tell me a bit about what resources are usually provided to new faculty members?" or "I wondered if you had any advice as I discuss the details of the job offer with [my negotiating partner]?" provides willing faculty an opportunity to share their institutional knowledge. Listen carefully both to what faculty members say and what they imply. If faculty explicitly say that some items are non-negotiable (usually salary or teaching load), heed their advice. Explaining to your negotiating partner that you understand that a certain item is non-negotiable and, therefore, that you are not going to negotiate for it goes a long way in generating goodwill. If one of the non-negotiable items means that you are no longer interested in accepting the offer, you are better equipped to bring the item up in a sensitive way during the negotiation.

Once you have learned all you can about negotiating at the institution, gather advice from as many colleagues as you can who work at similar institutions. Try to find institutions that match on as many characteristics as possible. For example, there are many research universities, but the advice most relevant to you comes from faculty at research universities with a similar size, location, cross-institution consortium, departmental degree offerings, departmental size and emphasis, and tenure standards. You may not know faculty at these "most similar" institutions: many faculty at these institutions will be responsive to an email explaining why you are contacting them and asking for advice. Alternatively, find faculty you or your advisors know that get as close to this list as possible.

By now, you will have amassed a vast amount of information and advice about negotiating, with perhaps twenty or more items people have suggested that you ask for. There are also countless online lists of recommended negotiation items. Only you can prioritize. One way to do this is to stop collecting information a few days before the negotiation, therefore reserving some time to think about your priorities. Remember that you are the one who may ultimately accept the job offer, not those from whom you received advice. Consider the tradeoff between negotiating over one-time resources like a new computer and longer-term benefits like salary. At the same time, the financial costs of taking a new job are high; ask for resources if the institution has not offered to provide them and if they will help you. 
The final step is conducting the actual negotiation, which most often occurs via phone. It may be helpful to prepare a script for yourself thanking your negotiating partner, expressing enthusiasm for the job offer, listing three or four negotiation items, and then describing each item in detail. The negotiation items you discuss should be your top negotiation priorities. It is good to have a mix of requests that you think that the institution can fulfill and items that may be a bit more challenging. Above all, choose the items that you need to be happy at that institution. Be clear about your intentions: are you almost ready to accept the job offer and these items are things you think will be beneficial or are these items required for you to accept? As you describe your items, focus on how each item helps the institution to succeed. For example, a course release benefits students because you have more time to carefully prepare appropriate teaching materials.

End the negotiation by asking about what happens next in the hiring process. Usually your negotiating partner will need to review the items you raised and get back to you with a revised job offer. At that point, if you are satisfied with the revised offer, signing the offer represents a formal commitment between you and the institution. Some additional approvals may be required, but those are typically pro forma. You can then turn your attention to getting ready for your new position!

You may decide that you are not interested in accepting the offer regardless of the outcome of negotiations or after the first round of negotiation. This too is a valid response to receiving a job offer, and you can communicate this to your negotiating partner via phone.

\section{Conclusion}

When you receive a job offer, you are undoubtedly excited. We recommend that you first pause and congratulate yourself on a successful search. Then, get to work on the negotiation.

Negotiations that are approached strategically and collegially are going to be the most successful. It will also be important for you to do your homework, getting to learn about your new place of work and your new colleagues. Both you and your future employer have an interest in maintaining collegiality throughout the process so that you start your new position with all sides feeling excited at the prospect of your employment. If you approach your negotiating process prepared and with realistic expectations, you will get off on the right foot as you start your career in academia. Employers will appreciate your reasonable approach to the negotiation process and you will leave feeling as if some of your needs were met. Good luck and welcome to the academy! 


\section{References}

Barron Lisa A. 2003. “Ask and you shall Receive? Gender Differences in Negotiators' Beliefs about Requests for a Higher Salary." Human Relations, 56(6): 635-662.

Claypool, Vicki Hesli, Brian David Janssen, Dongkyu Kim, and Sara McLaughlin Mitchell. 2017. "Determinants of Salary Dispersion Among Political Science Faculty." PS: Political Science \& Politics, 50(1): 146-156.

Perception Institute. 2021. "Implicit Bias." Research: Science \& Perception. https://perception.org/research/implicit-bias/.

Shonk, Katie. 2021. "Challenges Facing Women Negotiators." Harvard Law School Program on Negotiation Daily Blog, September 28. https://www.pon.harvard.edu/daily/leadershipskills-daily/women-and-negotiation-leveling-the-playing-field/. 